Relations industrielles

Industrial Relations

\title{
Laflamme, Roch, La vie dans les organisations: des indicateurs de succès
}

\section{Luc Brunet}

Volume 51, numéro 1, 1996

URI : https://id.erudit.org/iderudit/051088ar

DOI : https://doi.org/10.7202/051088ar

Aller au sommaire du numéro

Éditeur(s)

Département des relations industrielles de l'Université Laval

ISSN

0034-379X (imprimé)

1703-8138 (numérique)

Découvrir la revue

Citer ce compte rendu

Brunet, L. (1996). Compte rendu de [Laflamme, Roch, La vie dans les organisations: des indicateurs de succès]. Relations industrielles / Industrial Relations, 51(1), 222-223. https://doi.org/10.7202/051088ar

Tous droits réservés @ C Département des relations industrielles de l'Universite Laval, 1996
Ce document est protégé par la loi sur le droit d'auteur. L’utilisation des services d'Érudit (y compris la reproduction) est assujettie à sa politique d'utilisation que vous pouvez consulter en ligne.

https://apropos.erudit.org/fr/usagers/politique-dutilisation/ 
explications universelles : "Toute situation d'entreprise relève d'un niveau d'explication chaque fois différent"(p. 244). L'argumentation est complétée par des exemples et la dernière partie de l'ourrage est consacrée à l'étude empirique de quatre cas qui illustrent des situations d'identité et de culture; de traduction; de conventions ; de construction des règles. L'auteur préfère une position où il fait face à des faits sociaux qu'il doit interpréter en puisant dans des théories sans a priori.

Voilà un ouvrage qui innove sur plusieurs plans: (a) l'entreprise comme un objet autonome qui se détache de l'analyse des organisations; (b) les préceptes théoriques dont certains concepts n'ont pas été couramment utilisés à l'analyse des jeux d'acteurs dans l'entreprise, notamment la traduction utilisée essentiellement en sociologie de la science et de la technologie, les conventions qui servent d'amorce à un nouveau programme de recherche; la confiance qui malgré sa résurgence reste un concept vague ; (c) la posture méthodologique qui emprunte à Feyerabend le "tout est bon " et cherche à tenir compte d'une pluralité de situations évolutives. Cela semble excessif mais seule l'épreuve du temps saura nous indiquer si ces innovations traverseront les bouleversements que connaît l'entreprise comme objet d'analyse que ces concepts aideront à faire comprendre et à expliquer.

Le débat sur l'existence d'une sociologie de l'entreprise ne s'achèvera certainement pas avec la publication de ce volume. Au contraire, il est lancé à supposer que les sociologues en provenance d'autres horizons culturels et théoriques prendront le relais et sauront y intégrer d'autres développements sur les organisations post-modernes et l'entreprise. Par exemple, les ouvrages de Stewart R. Clegg, Modern Organizations: Organization Studies in the Postmodern World (Sage Publications, London, 1990) et de John Hassard et Martin Parker, Postmodernism and Organizations (Sage Publications, London, 1993) rompent également avec les positions conceptuelles et méthodologiques de la sociologie classique des organisations. Bernoux présente essentiellement les dernières positions théoriques développées en France, ce qui témoigne de la vitalité de la sociologie française. Ailleurs, le débat porte moins sur la constitution d'un nouvel objet que sur la rupture d'avec la conception classique des organisations. Il n'est pas question de désigner l'objet autrement que par le terme " organisation " qui comprend également des lieux de coordination d'activités non productives tels les syndicats, les partis politiques, les Églises, les organismes à but non lucratif, etc.

En somme, voilà un ouvrage qui constitue une bonne synthèse des innovations conceptuelles sur l'entreprise et qui sont clairement exposées par Philippe Bemoux. Le livre ne fait pas que le point sur le sujet, il propose des pistes de recherche et renouvelle le champ d'analyse avec de nouveaux outils conceptuels et des applications empiriques. La lecture est stimulante et je la recommande à tout praticien, étudiant et professeur intéressés par le sujet.

DENIS HARRISSON

Université du Québec à Hull

\section{La vie dans les organisations: des indicateurs de succès}

par Roch LAFLAMME, Sainte-Foy, Presses de l'Université du Québec, 1994, 59 p., ISBN 2-7605-0782-3.

La monographie de 60 pages de Roch Laflamme présente un bon résumé de quatre concepts de base importants en comportement organisationnel. Ce sont les concepts de satisfaction au travail, de climat organisationnel, de qualité de vie au travail et de culture organisationnelle. L'auteur conclut son travail par une des- 
cription des indicateurs communs aux quatre concepts. Chaque chapitre se caractérise toujours par une description des principales dimensions du concept telles qu'élaborées par un certain nombre de chercheurs.

Le concept de satisfaction au travail est abordé comme celui qui a présidé à l'émergence des autres concepts présentés dans cette monographie. L'auteur mentionne aussi que l'examen des définitions de la satisfaction au travail exige, s'il veut être complet, que les termes " moral ", " attitude ", " opinion " et "satisfaction " soient considêrés comme synonymes, même si sur le plan théorique, il est possible de les distinguer. Un tableau regroupant des indicateurs de satisfaction au travail selon huit auteurs est aussi présenté et l'auteur conclut cette section en retenant quatorze des indicateurs qui reviennent le plus souvent et qui sont considérés par ce dernier comme très importants, ce sont : le travail lui-même, le salaire, l'avancement, la supervision humaine, l'autonomie, les collègues de travail, les conditions de travail, la reconnaissance/considération, le degré de responsabilité, la variété, la sécurité d'emploi, la communication, l'information et les politiques de l'organisation.

La notion de climat organisationnel est dans un premier temps distinguée de celle portant sur la satisfaction au travail et, dans un deuxième temps, définie comme une série d'attributs propres à une organisation qui la distingue des autres dans ses comportements avec ses membres et son environnement. Ici aussi on retrouve une étude comparative de différents chercheurs qui ont suggêré des indicateurs du climat organisationnel. De l'analyse de leurs travaux, l'auteur dégage vingt-quatre indicateurs du climat et mentionne que ceux portant sur le processus organisationnel jouent un plus grand rôle dans le climat organisationnel que les variables structurelles.

Le concept de qualité de vie au travail est présenté selon une approche his- torique et théorique. La définition de cette notion qui est retenue ici évoque une façon de concevoir le travail et l'organisation du travail fondée sur des principes qui tiennent compte de la personne. Elle désigne un mode de vie au travail mettant en valeur l'être humain plutōt que des objets.

L'auteur présente ensuite la notion de culture organisationnelle en la distinguant de celle du climat avec laquelle elle est souvent confondue dans la documentation. Après un examen des études de différents chercheurs proposant des définitions de la culture, le modèle de Schein (1989) est ici retenu. Ce dernier mentionne qu'on peut aborder la culture organisationnelle selon trois niveaux distincts mais liés entre eux : (1) les artefacts et les créations, (2) les valeurs, (3) les croyances fondamentales. Pour comprendre sa culture, il faut être conscient des éléments qui la constituent et savoir comment on peut la révéler. Pour comprendre la gestion d'une entreprise, il faut être conscient de l'influence d'une culture sur le comportement interne et stratégique d'une organisation, et cela pour la gestion efficace de n'importe quelle entreprise compétitive.

Finalement, dans la dernière partie de cette monographie, l'auteur fait une étude comparative de tous les indicateurs de concepts utilisés dans les études portant sur la satisfaction au travail, le climat organisationnel, la qualité de vie au travail et la culture organisationnelle. Il en déduit, suite à l'analyse des définitions et des indicateurs, que sept d'entre eux ont pu résister aux approches conceptuelles, aux philosophies de gestion et même aux modes, ce sont: le salaire ou la rémunération, la supervision, les collègues, l'autonomie, les conditions physiques de travail, la communication et les politiques. 